\title{
IGNITION OF A GASEOUS METHANE/OXYGEN COAXIAL JET
}

\section{Pauly, J. Sender, and M. Oschwald}

Ignition and flame anchoring of a coaxial gaseous methane-oxygen jet have been studied using high-speed visualization techniques. Several ignition scenarios ("blowout," "smooth," and "strong ignition") have been found with specific phenomenology depending, mainly, on the time delay between propellant valve opening and ignition. The time necessary for flame anchoring is shown to depend on the mass flow rate. Attached and detached flames are observed and it is found that high momentum flux ratios favour the establishment of a flame attached to the injector. For detached flames, higher chamber pressures result in smaller liftoff distances.

\section{NOMENCLATURE}

$\begin{array}{ll}\mathrm{CC} & \text { combustion chamber } \\ d, D & \text { inner diameter, outer diameter } \\ \text { fps } & \text { frames per second } \\ \mathrm{GO}_{2} & \text { gaseous oxygen } \\ \mathrm{GCH}_{4} & \text { gaseous methane } \\ J & \text { momentum flux ratio, } J=\left(\rho u^{2}\right)_{\mathrm{CH}_{4}} /\left(\rho u^{2}\right)_{\mathrm{O}_{2}} \\ \dot{m} & \text { mass flow rate } \\ p, P & \text { pressure } \\ R_{\text {of }} & \text { mixture ratio, } R_{\mathrm{of}}=\dot{m}_{\mathrm{O}_{2}} / \dot{m}_{\mathrm{CH}_{4}} \\ T & \text { temperature } \\ u & \text { injection velocity } \\ V_{\text {ratio }} & \text { velocity ratio, } V_{\text {ratio }}=u_{\mathrm{CH}_{4}} / u_{\mathrm{O}_{2}} \\ \rho & \text { density } \\ \Phi & \text { equivalence ratio }\end{array}$

\section{INTRODUCTION}

Hydrogen is one of the most widely-used fuels for liquid rocket engines notably because, in burning with oxygen, it delivers the highest specific impulse and 
produces only environmentally friendly water vapor. However, the limitations imposed by cryogenic hydrogen are more in production (costs), handling, and storing operations (very low density). The best performing nontoxic substitutes, "green propellants," have been found in hydrocarbons, among these methane and kerosene are particularly promising. These candidates present several advantages like higher density, reduced handling effort (reduced safety precautions), and easier storage (lower cooling effort). Moreover, several precedent studies have highlighted specific advantages of methane [1], namely, better cooling capabilities, a higher specific impulse, and lower coking and sooting propensities (at both, the cooling channel and combustion chamber walls).

For many years, the ignition phenomenon has been a crucial issue for liquid propellant rocket engines. During Ariane flights V15 and V18, deficiencies appeared at the start-up of the cryogenic upper stage engine (HM7B) which were responsible for the mission failure [2]. Moreover, the multiple payload capability of the Ariane 5 launcher requires the upper stage engine to be reignitable that means to ensure a reproducible, safe, and reliable ignition, without flame blowout and without overpressure inside the combustion chamber.

The use of new "green propellants" like methane induces also new combustion behavior, especially, with respect to flame stabilization during steady state combustion. While with hydrogen fuel, the flame anchors properly at the injector lips in most cases [3-6], the use of methane fuel induces differences in flame stabilization. The flame behavior appears to be highly dependent on injection and combustion chamber conditions: for supercritical injected propellants, the $\mathrm{LOX} / \mathrm{CH}_{4}$ flame stabilizes near the injector $[4,7]$; however, for subcritical condition, the methane flame can stabilize either anchored or detached $[3,5,8]$. Even though the laminar flame velocity for methane-oxygen mixture is about a factor of 2.7 lower than that for hydrogen-oxygen mixture [9], the reasons explaining the flame behavior difference are up to now not clear and further investigations are still going on to better understand the mechanisms of methane flame stabilization.

Modeling of reactive two-phase flows under transient conditions is still challenging and confidence in the prediction capability of models and numerical simulations is still limited. In using only gaseous propellants, this experimental study is especially dedicated to be used as test case for computational fluid dynamics (CFD) simulations. The precedent experimental investigation on ignition of a gaseous $\mathrm{H}_{2} / \mathrm{O}_{2}$ coaxial jet $[10,11]$ has already been computed with CFD tools by several groups $[12,13]$, thus demonstrating the interest to such experimental studies. Former studies have also been addressed to the investigation of liquid methane/oxygen ignition phenomena and flame stabilization $[3,5,14]$.

The experimental work presented here focuses on the ignition transient and the process of flame stabilization of a gaseous $\mathrm{CH}_{4} / \mathrm{O}_{2}$ coaxial jet, and also addresses particular attention to providing detailed data for validation of CFD tools. 


\section{EXPERIMENTAL SETUP}

\subsection{Combustion Chamber}

The experiments have been performed at the M3.1 Micro-Combustor Test Facility in DLR Lampoldshausen (Germany). The test bench is composed of a horizontally mounted rectangular combustion chamber equipped with quartz windows providing complete optical access to the combustor volume (Fig. 1). The dimensions of the chamber are $60 \times 60 \times 140 \mathrm{~mm}$. The combustion chamber is equipped with a single coaxial injector without recess and without tapering. The inner diameter of oxygen injector as well as the outer diameter of methane injector can be varied in order to achieve different injection conditions (Table 1). Different nozzle geometries at the exit of the chamber can also be chosen in order to adjust chamber pressures. The dome geometry is shown in Fig. 2.

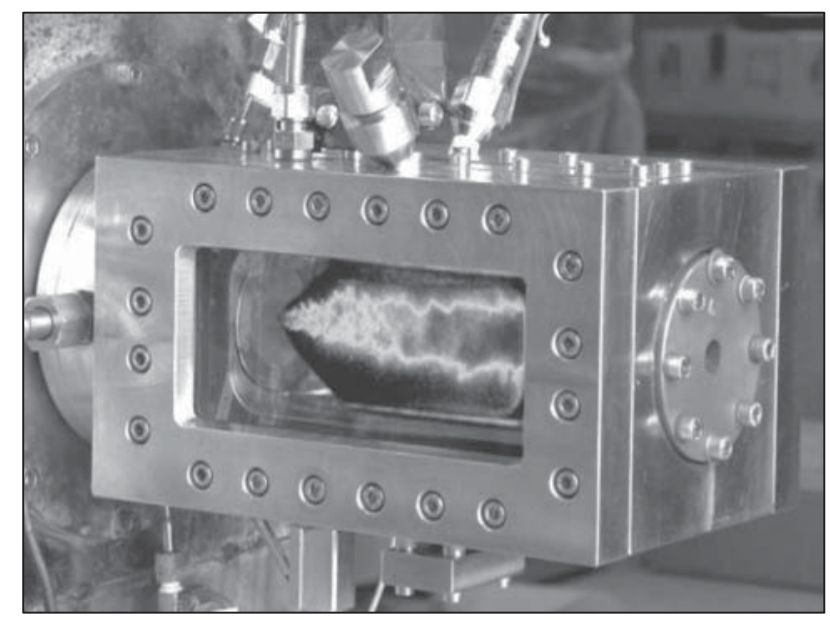

Figure 1 Microcombustion chamber

Table 1 Injector, combustion chamber geometries and test conditions

\begin{tabular}{lcccccccccc}
\hline \multirow{2}{*}{ Test case } & $\begin{array}{c}d_{\mathrm{O}_{2}}, \\
\mathrm{~mm}\end{array}$ & $\begin{array}{c}D_{\mathrm{O}_{2}}, \\
\mathrm{~mm}\end{array}$ & $\begin{array}{c}D_{\mathrm{CH}_{4}}, \\
\mathrm{~mm}\end{array}$ & $\begin{array}{c}D_{\mathrm{CC}}, \\
\mathrm{mm}\end{array}$ & $\begin{array}{c}P_{\mathrm{CC}}, \\
\text { bar }\end{array}$ & $\begin{array}{c}\dot{m}_{\mathrm{tot}\left(\mathrm{O}_{2}+\mathrm{CH}_{4}\right)}, \\
\mathrm{g} / \mathrm{s}\end{array}$ & $\begin{array}{c}u_{\mathrm{CH}_{4}}, \\
\mathrm{~m} / \mathrm{s}\end{array}$ & $\begin{array}{c}u_{\mathrm{O}_{2}}, \\
\mathrm{~m} / \mathrm{s}\end{array}$ & $J$ & $V_{\text {ratio }}$ \\
\hline Case A & 1.6 & 2.4 & 4.0 & 6 & 1.5 & 3.1 & 133 & 304 & 0.02 & 0.33 \\
Case B & 2.5 & 3.3 & 4.3 & 6 & $1.5-3.6$ & $3.1-5.9$ & $212-359$ & 298 & 0.13 & 0.54 \\
Case C1 & 2.5 & 3.3 & 3.6 & 6 & 2.3 & 4.6 & 424 & 305 & 1.53 & 1.72 \\
Case C2 & 2.5 & 3.3 & 3.6 & 4 & 2.3 & 2.1 & 351 & 201 & 1.56 & 1.74 \\
Case D & 2.5 & 3.3 & 4.0 & 6 & 2.3 & 4.6 & 368 & 302 & 0.30 & 0.81 \\
\hline
\end{tabular}




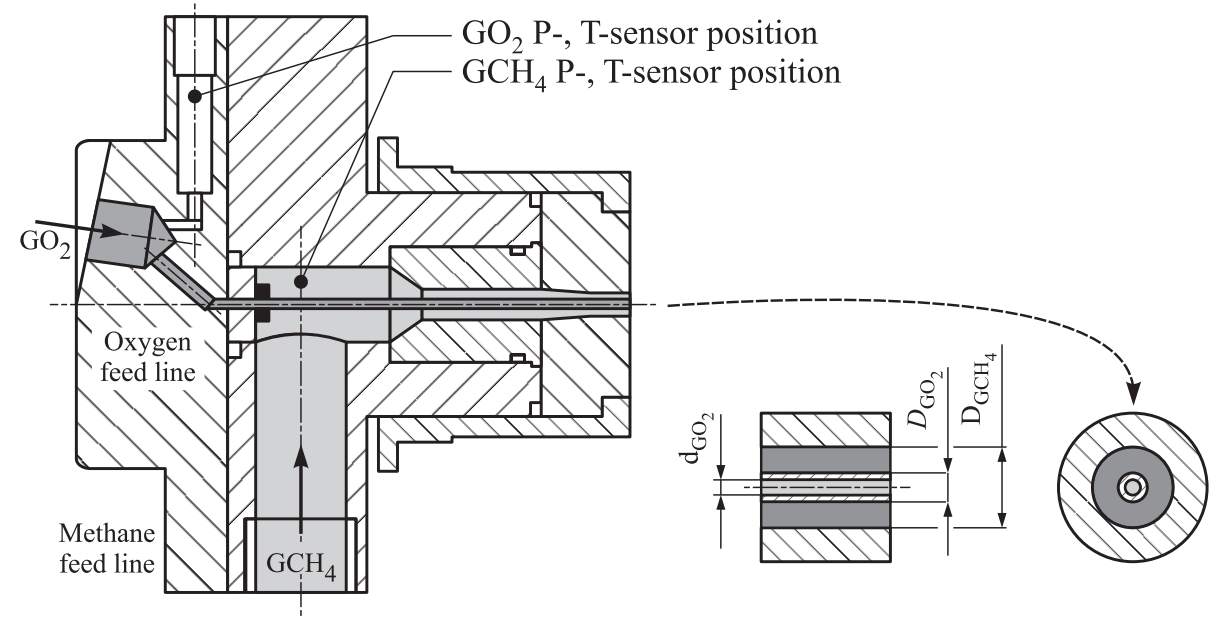

Figure 2 Dome geometry of the methane/oxygen injector

\subsection{Laser Ignition}

The ignition system is provided by a frequency doubled Nd-YAG laser. The laser beam is focused into the chamber inducing a gas breakdown in its focus and creating plasma in the flow (Fig. 3). The laser pulse of 10-nanosecond duration provides energy of about $150 \mathrm{~mJ}$. No data on laser energy thresholds have been found for $\mathrm{CH}_{4} / \mathrm{O}_{2}$ mixtures in literature. For premixed methane/air mixtures, the minimum ignition en-

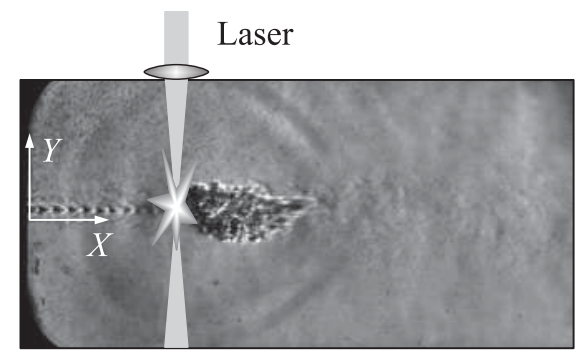

Figure 3 Laser beam focused inside the chamber ergy is reported to be about $4 \mathrm{~mJ}$ for an equivalence ratio of 1.2 [15].

Though laser ignition is not representative for a traditional pyrotechnic igniter, it has advantages in terms of precision of ignition location and exact control of ignition time. The data recording of cameras and sensors can be very precisely synchronized with the igniting laser pulse (precision of $\pm 10 \mu \mathrm{s}$ ). The location of the ignition was set to $31 \mathrm{~mm}$ downstream the injector plate and $1 \mathrm{~mm}$ off jet axis. The approximate size of the induced plasma kernel has been determined from $\mathrm{OH}$ emission and Schlieren imaging as $d X_{\text {plasma }}=2.25 \mathrm{~mm}$ and $d Y_{\text {plasma }}=3.4 \mathrm{~mm}$. 


\subsection{Optical Diagnostic Systems}

A standard Z-Schlieren setup was used with two different zoom settings, recording the images with a high-speed charge-coupled device (CCD) camera at $2000 \mathrm{fps}$ and a resolution of $512 \times 256$ pixels. For the first two test cases A and $\mathrm{B}$ (for the definition of test cases see below), an area of $40 \times 80 \mathrm{~mm}$ positioned directly at the injector exit was chosen to have a better resolution in this region. Test cases $\mathrm{C} 1, \mathrm{C} 2$, and $\mathrm{D}$ are recorded using a smaller magnification imaging area of $60 \times 110 \mathrm{~mm}$. An example of a Schlieren image for the latter zoom can be seen in Fig. 3 .

Additionally, the chemiluminescence of intermittently existing $\mathrm{OH}$-radicals is recorded by a high-speed intensified CCD (ICCD) camera. In this case, the complete combustion chamber is visualized with a resolution of $512 \times 256$ pixels and a frame rate of 12500 fps. A band-pass filter $(310 \pm 5 \mathrm{~nm})$ is used to select only the emission of the OH-radical.

The recorded $\mathrm{OH}$ emission images have been postprocessed using image processing tools. A false-color representation of the black and white images was chosen in order to get a better visualization of the intensity gradient. The flame boundary is determined by separating the flame from the background by using adequate threshold values to remove noise such as signals due to reflection from the combustor walls. The specific threshold for each test condition has been chosen depending on the image and the camera characteristics. Values typically ranging from 10\%-30\% of full gray scale have been found adequate. Finally, images were averaged during steady state combustion to determine the final liftoff

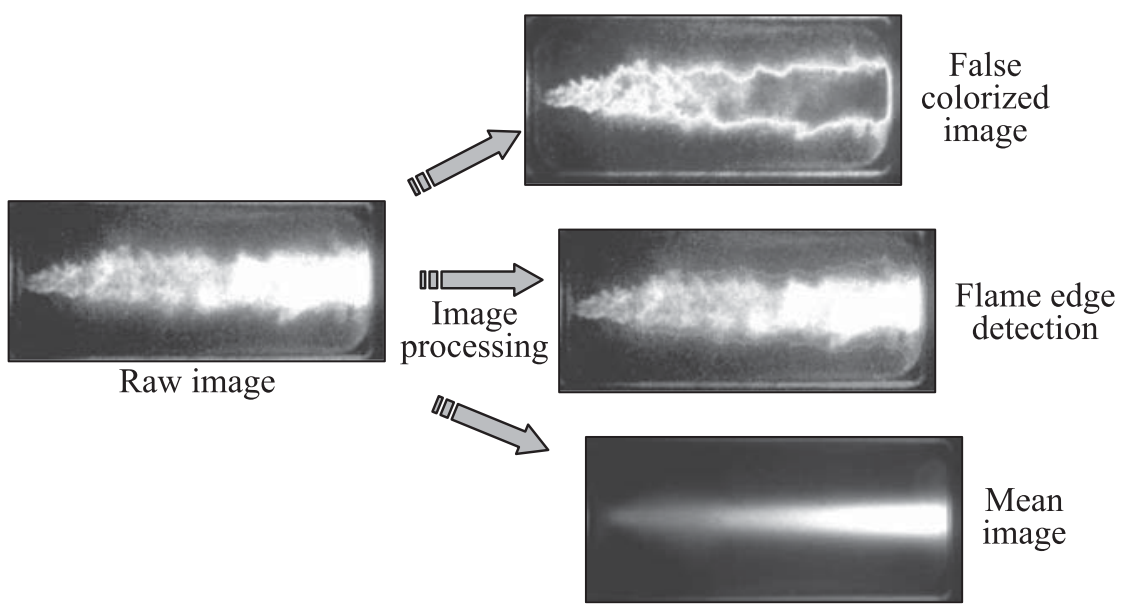

Figure 4 Image processing performed on $\mathrm{OH}$ images 
distance of the flame (distance from the injector plate to the upstream flame front). Figure 4 illustrates the image processing steps.

\subsection{Test Time Sequence}

The chamber is continuously purged with nitrogen until $3000 \mathrm{~ms}$ before ignition time, so that it can be considered as completely filled with nitrogen. The fuel valve is opened around $40 \mathrm{~ms}$ before the oxidizer valve in order to have fuel-rich mixture at the ignition time. After stationary flow conditions in the injector dome are reached (typically, around $80 \mathrm{~ms}$ for methane and $50 \mathrm{~ms}$ for oxygen after that the first rise of dome pressure sensor occurs) ignition is triggered. The duration of the hot flow run is $1 \mathrm{~s}$.

\subsection{Test Conditions}

Four test cases (A, B, C, and D) have been performed in modifying the geometrical characteristics of the injector (see Table 1 ). Test case A, with an oxygen injector diameter of $1.6 \mathrm{~mm}$, was chosen for comparison with a precedent $\mathrm{GH}_{2} / \mathrm{GO}_{2}$-test case. However, during tests, no attached flame was observed with this configuration. Test cases B through D have been set up with an enlarged diameter to reduce the oxygen injection velocity. With this configuration, three different methane annular slit diameters were used to study the influence of the methane velocity (B, C, and D). The steady state chamber pressure has been varied for the test case B from 1.5 to 3.6 bar. An additional test case (C2) was run with a smaller chamber nozzle, 4 -millimeter instead of 6-millimeter diameter, in order to study the influence of the mass flow rate. The propellant mixture ratio was kept for all tests at $R_{\text {of }}=3.4(\Phi=1.2)$.

The global geometrical characteristics and injection conditions are summarized in Table 1 . The velocities are computed before ignition time while momentum flux ratio $J=\left(\rho u^{2}\right)_{\mathrm{CH}_{4}} /\left(\rho u^{2}\right)_{\mathrm{O}_{2}}$ and velocity ratio $V_{\text {ratio }}=u_{\mathrm{CH}_{4}} / u_{\mathrm{O}_{2}}$ are given during steady combustion. Due to experimental constraints, velocity ratio and momentum flux ratio could not be varied independently; the two parameters are strongly correlated.

\section{IGNITION PHENOMENOLOGY}

\subsection{General Remarks}

Based on the evaluation of the $\mathrm{OH}$ - and Schlieren-imaging, the existence of three different ignition scenarios has been observed. A nonreliable ignition where the 


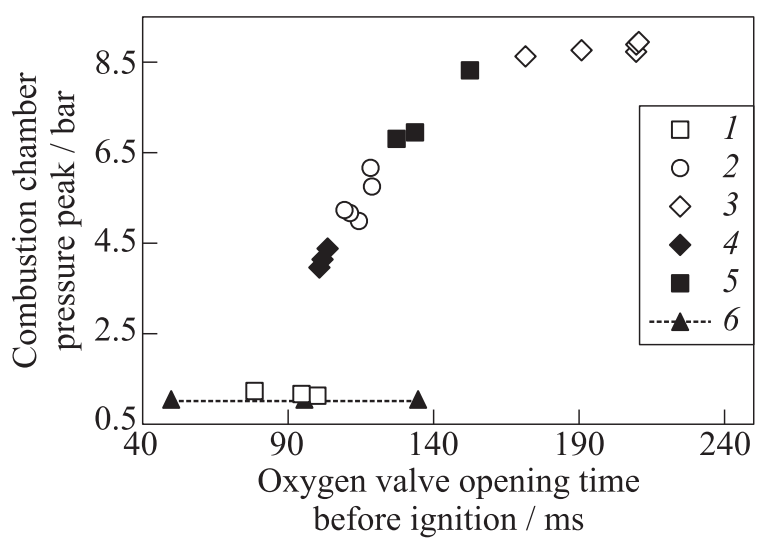

Figure 5 Ignition scenario dependency with respect to the opening time: 1 Blowout Ignition (BoI); 2 - Smooth Ignition (SmI); 3 - Strong Ignition (StI); 4 BoI-SmI; 5 - SmI-StI; and 6 - cold flows

flame is blown out and extinguished has been found (see subsection 3.2) and two successful other ignition types: one with smooth evolution of the flame front and of the chamber pressure, the other one with much stronger transient phenomenology (see subsection 3.3). Moreover, during each reliable ignition scenario, three different transient phases have been highlighted, characterizing the evolution of the flame front. These are, in order of appearance: a blowdown phase where the flame is blown downstream (or even extinguishes); an expansion phase where the flame increases in size and intensity; and finally, a stabilization phase where the flame stabilizes either in detached or attached position. The duration of each phase depends on several parameters like injection conditions. Typically, the blowdown phase lasts between 0.5 and $1.5 \mathrm{~ms}$ and the expansion phase between 6 and $17 \mathrm{~ms}$ after ignition.

An important parameter determining how distinct each phase is developed and thus determining which ignition scenario occurs is the time delay between opening of the propellant valves and the laser pulse.

Figure 5 illustrates this phenomenon giving the ignition peak pressures for tests performed with different valve opening times (test case A). Extending this delay increases the mass of unburnt gases in the chamber, thus resulting in higher pressure peaks at ignition time. For too short delays, only the first ignition phase (blowdown phase) is observed and the flame extinguishes, while when increasing the delay, the ignition becomes reliable but with differences in the expansion phases. For very long ignition time delays (see Fig. 8), it leads to a direct and significant expansion of the flame without relevant blowdown of the initial flame kernel (strong ignition). 


\subsection{Blowout Scenario}

In this scenario, the flame kernel is blown down towards the exit nozzle just after ignition and extinguishes. Due to the small delay between valve opening and ignition, there is still a reasonable amount of nitrogen in the chamber. This nitrogen is mixed into the reactive $\mathrm{CH}_{4} / \mathrm{O}_{2}$-shear layer and the flame is quenched. Figure 6 depicts such a blowout ignition where the images are displayed for time intervals of 1.44 and $1.5 \mathrm{~ms}$ for $\mathrm{OH}$ (top) and Schlieren (bottom) imaging, respectively. The propellants are exhausting from the injector on the left of the images. The first Schlieren images show a blast wave created by the focused laser beam and the crossed-shock structures at the exit of the oxygen injector, characteristics of an underexpanded jet and confirming the sonic condition of the oxygen jet at ignition time.

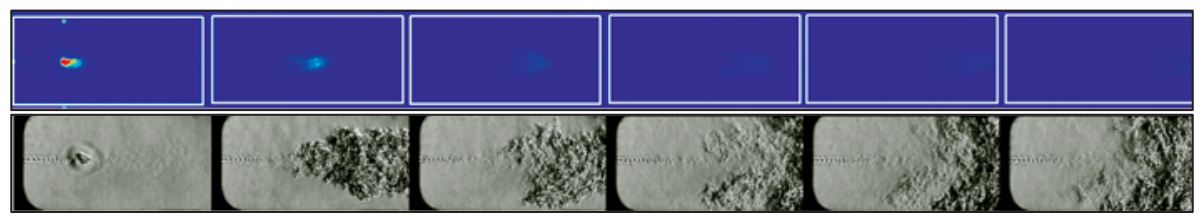

Figure $6 \mathrm{OH}$ and Schlieren images of blowout scenario (0 to . $7.5 \mathrm{~ms}$ ). (Refer Pauly et al., p.162.)

\subsection{Smooth and Strong Ignition Scenarios}

During the blowdown phase, hot gas expands depending on the accumulated amount of reactants before ignition, more or less rapidly. For reliable ignition cases, this expansion passes over into the so-called expansion phase. The hot gases expand both in the upstream and downstream directions. The hot gases moving in the downstream direction are redirected in the recirculation zone at the combustor exit, recirculate and realign along the central propellant jet. The interaction of these hot gases with the unburnt and colder propellants leads to an efficient local mixing allowing the propagation of the flame towards the injector. In this case, the flame front velocity is high enough (in comparison with the propellants injection velocity) to allow the attachment of the flame at the injector lips. Figure 7 depicts such a smooth ignition where the images are displayed for time intervals of 0.44 and $0.5 \mathrm{~ms}$ for $\mathrm{OH}$ (top) and Schlieren (bottom) imaging, respectively.

In case of a longer delay between valve opening and ignition the sudden consumption of all accumulated propellants induces a high chamber pressure 


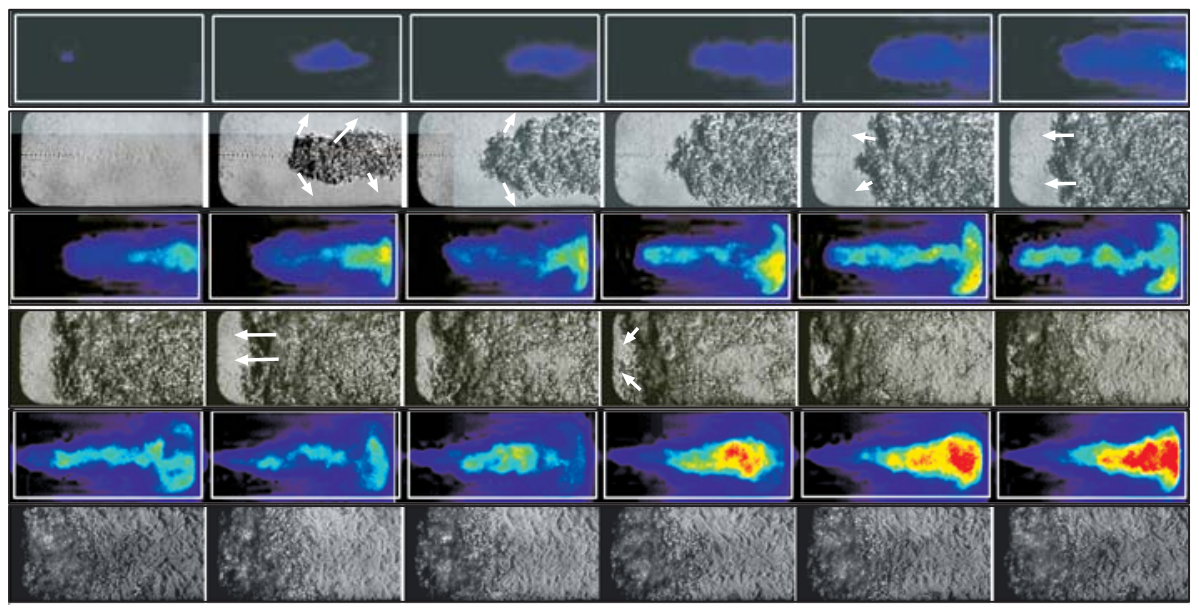

Figure $7 \mathrm{OH}$ and Schlieren images of a smooth ignition scenario (0 to $\sim 8.5 \mathrm{~ms})$. (Refer Pauly et al., p. 163.)

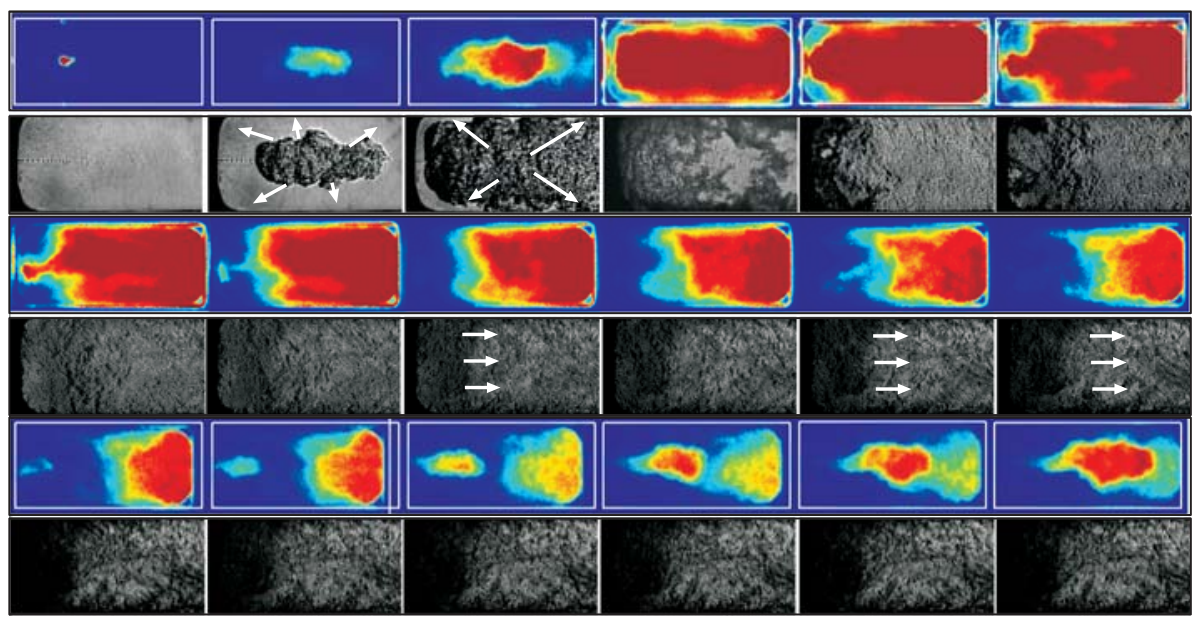

Figure $8 \mathrm{OH}$ and Schlieren images of a strong ignition scenario (0 to $\sim 8.5 \mathrm{~ms})$. (Refer Pauly et al., p. 163.)

peak, i.e., a strong ignition. The exhaust of propellants is choked and a backflow of gases from the chamber into the injector dome occurs.

This phenomenon is observed due to the dome pressure readings. This is also supported by an analysis of $\mathrm{OH}$ emission images (Fig. 8) where after $4 \mathrm{~ms}$ the flame extinguishes at injector lips, detaches from the injector plate and is 
blown out. After a certain delay (at around $6 \mathrm{~ms}$ ), a reignition is observed in proximity to the injector exit.

\subsection{Influence of Propellant Injection Velocity}

Two test cases ( $\mathrm{C} 1$ and $\mathrm{C} 2$ ) have been defined to investigate the role of the propellant injection velocity on the ignition phenomenology. Injector dimensions, mixture ratio, momentum flux and velocity ratio, and combustion chamber pressure were identical for steady state combustion in both test cases whereas the propellant mass flow was higher in case C1 by a factor of 2.2 as compared to C2 (see Table 1). As a result, the injection velocities were also higher in test case $\mathrm{C} 1$ as in case $\mathrm{C} 2$ at the time of ignition. The delay between valve opening and ignition was adjusted to result in similar amounts of unburnt gas in the chamber prior to ignition. Both test cases show smooth ignition behavior.

For both test cases, the flame evolution during the ignition transient is tracked by determining the position of the upstream flame front (distance to the injector plate) from $\mathrm{OH}$ emission images. The data are shown in Fig. 9. The different ignition phases discussed above are clearly visible. However, there are particular differences between both cases.

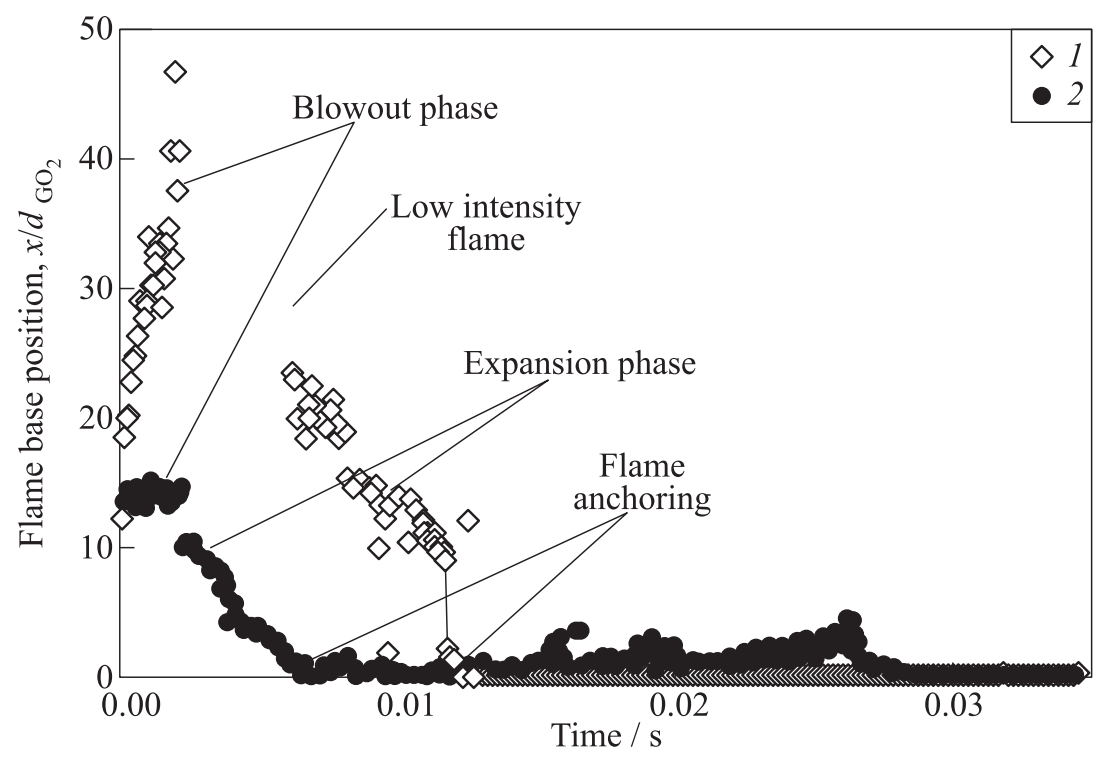

Figure 9 Flame base position for attached flames with different mass fluxes: 1 high (test case C1-25-11) and 2 - low (test case C2-26-16) 
For the high mass-flow case $\mathrm{C} 1$, the flame is blown down to a large distance from the injector plate. The flame intensity is strongly decreasing and rather no more visible; for that reason, between 2 and $6 \mathrm{~ms}$ the flame front could not be tracked. When the flame expands into upstream direction during the expansion phase, chemiluminescence recovers at a position several diameters downstream the injector. From there, the flame base moves slowly towards the injector and finally anchors there. The phenomenon of very low chemiluminescence intensity has also been observed in former investigations, especially with $\mathrm{CH}_{4} / \mathrm{LOX}$ [14].

In the low mass-flow case $\mathrm{C} 2$, the upstream flame front is not blown down and starts after $2 \mathrm{~ms}$ to move upstream. For both test cases, the upstream flame front movement is found to have similar velocity, although the propellant velocities are much higher in case $\mathrm{C} 1$ as compared to $\mathrm{C} 2$. Attachment occurs at around $6 \mathrm{~ms}$ for case $\mathrm{C} 2$, earlier than the 12.5 ms required in the higher mass-flow case $\mathrm{C} 1$.

Once anchored, the flames stayed stabilized at the injector during the rest of the steady combustion for both cases.

\section{FLAME STABILIZATION}

Figure 10 shows flame images of the stabilization phase, i.e., the period between the end of the flame expansion and the final steady state combustion for all injection conditions (A, B, C1, C2, and D). The images have been averaged during the time period between 40 and $120 \mathrm{~ms}$ after ignition, they are aligned with decreasing lift off distance. Table 2 shows the measured momentum flux ratio $J$ and velocity ratio $V_{\text {ratio }}$ for the specific tests.

It can be clearly seen that for low values of velocity ratio and $J$ number, the flame stays at a significant distance from the injector lips (more than 15 times the inner oxygen injector diameter). Above a critical value of the momentum flux ratio $J$ or velocity ratio, the flame becomes stable and stays attached at the injector lips. The shape of the flame depends whether it is attached or detached. Detached flames exhibit a parabolic-like shape with the maximum intensity localized at the head of the flame. With increasing $J$, the flame head moves upstream and its shape changes to a divergent cone, when it is attached to the injector.

For the attached flame, the maximum flame emission moves upstream with increasing momentum flux ratio and the flame angle is increasing too. Figure 11 shows this correlation more clearly by collecting all tests performed in a $J-V_{\text {ratio }}$ plot. The critical values of 0.29 and 0.8 for $J$ and $V_{\text {ratio }}$, respectively, appear to separate the two flame stabilization regions observed during this test campaign.

For detached flames (case B), the tests show a dependency of the liftoff distance on the chamber pressure for steady state conditions. Increasing the chamber pressure results in a reduction of the liftoff distance and favours 


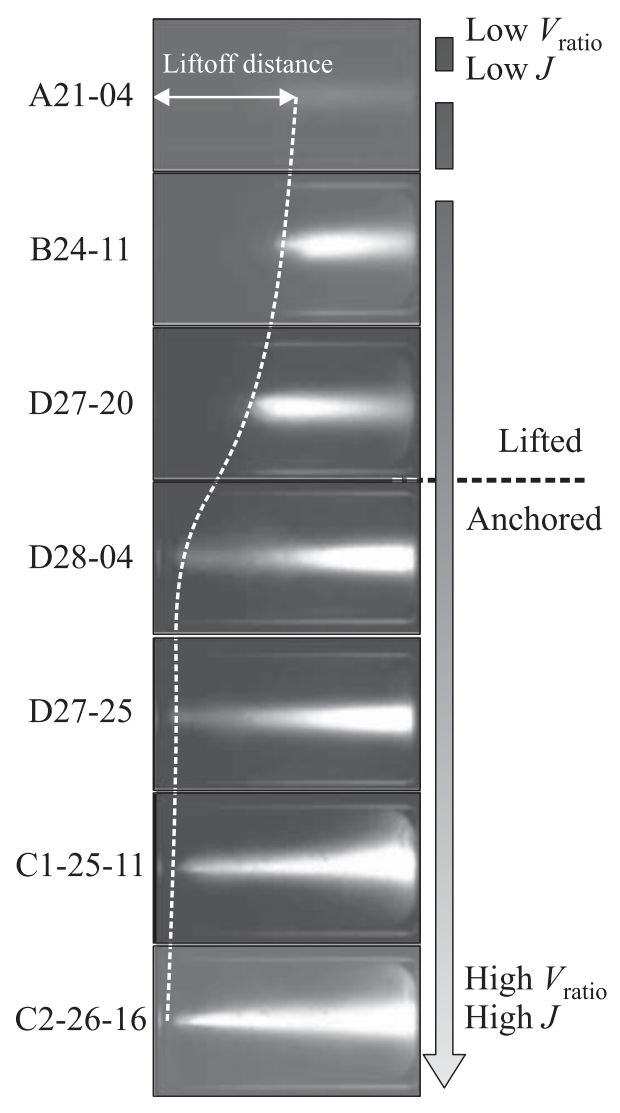

Figure 10 Lifted and anchored flames

Table 2 Measured $J$ number and $V_{\text {ratio }}$

\begin{tabular}{lccc}
\hline Test case & Test No. & $J$ & $V_{\text {ratio }}$ \\
\hline A & $21-04$ & 0.02 & 0.32 \\
B & $24-11$ & 0.13 & 0.54 \\
D & $27-20$ & 0.26 & 0.75 \\
D & $28-04$ & 0.29 & 0.80 \\
D & $27-25$ & 0.32 & 0.85 \\
C1 & $25-11$ & 1.52 & 1.72 \\
C2 & $26-16$ & 1.59 & 1.77 \\
\hline
\end{tabular}

the attachment of the flame. The flame liftoff distance as a function of chamber pressure is shown in Fig. 12, the liftoff distance $x / d_{\mathrm{O}_{2}}$ decreases from 30 to less than 15 when increasing $P_{\mathrm{CC}}$ from 1.5 to 3 bar.

For the lifted flames in case A and $\mathrm{B}$, an oscillation of the flame base position is observed after the ignition pressure peak has occurred. Figure 13 shows this phenomenon for test case B. The oscillation frequency is around $100 \mathrm{~Hz}$, the amplitude of the 


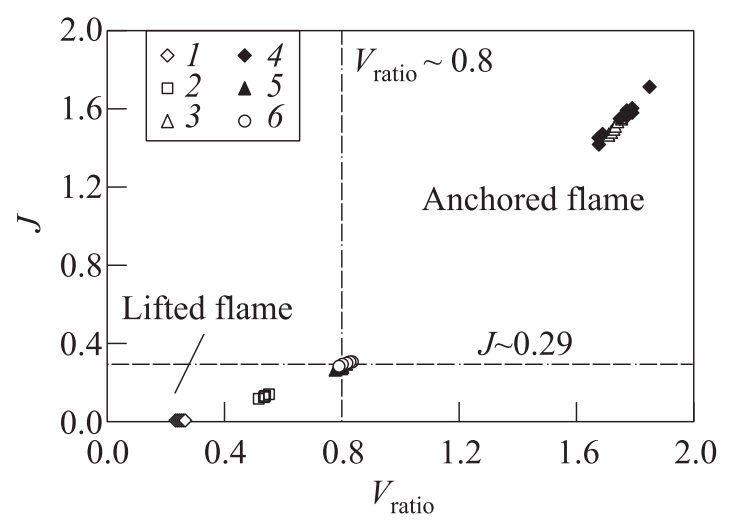

Figure 11 Tests with stable and lifted flame: 1 - test case A; $2-\mathrm{B} ; 3-\mathrm{C} 1 ; 4-$ C2; 5 - D27; and 6 - test case D28

oscillation is seen to decrease when approaching steady state combustion. The oscillation frequency corresponds to the $1 \mathrm{~L}$-mode found in a modal analysis of the $\mathrm{O}_{2}$-feed line. Thus, there is indication that this lowfrequency (LF) oscillation corresponds to a coupling between the $\mathrm{O}_{2}$-propellant feed line and the combustion chamber. Lowfrequency oscillations of this type have also been observed in real rocket engines [16]. How-

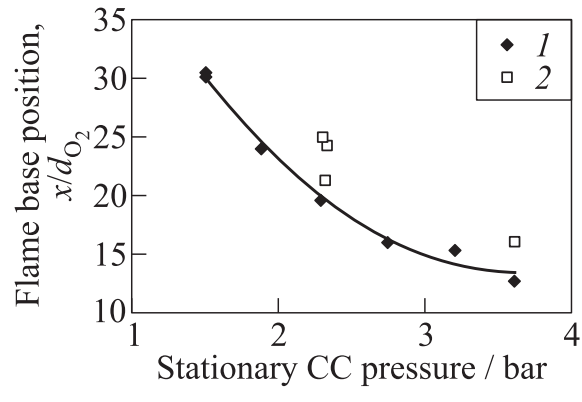

Figure 12 Liftoff distance for different $P_{\mathrm{CC}}$ : 1 - Shutter $30 \mu \mathrm{s}$ and 2 - Shutter $20 \mu \mathrm{s}$ ever, in the present setup, the feed system was decoupled from the combustion chamber by a sonic nozzle of sufficient pressure ratio to guarantee decoupling also when the ignition pressure peak occurs. Thus, the interpretation is still under analysis.

\section{SUMMARY AND CONCLUDING REMARKS}

The transient process following laser-induced ignition of a coaxial $\mathrm{CH}_{4} / \mathrm{O}_{2}$-jet has been found to follow different scenarios of specific phenomenology: flame blowout, smooth, and strong ignition. Which scenario is realized is strongly controlled by the delay between the propellant valve opening time and the ignition 


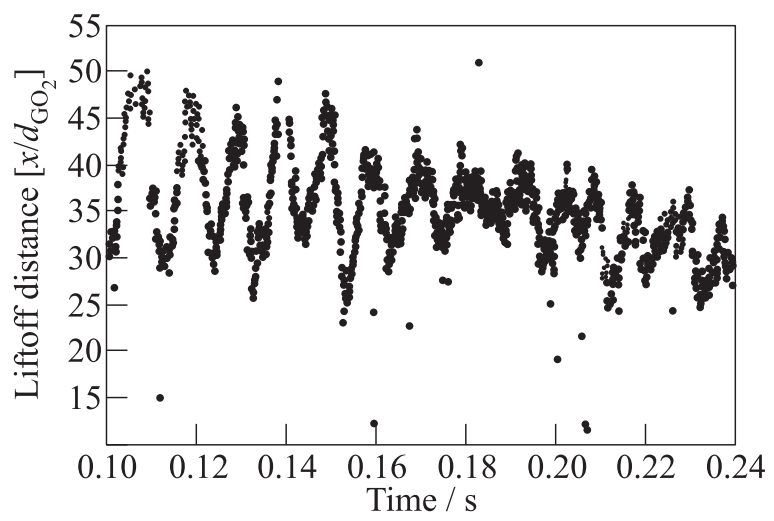

Figure 13 Low-frequency oscillations of combustion: liftoff distance during flame stabilization (test case B-24-02)

time. The amount of unburnt gas in the combustor at the time of ignition has a major influence on the ignition transient.

Increasing the mass flow rate is resulting in a prolongation of the time to stabilize the flame. The flame is convected downstream at a longer distance by the higher injection velocities in this case before it moves upstream again due to the expansion of the flame kernel.

Momentum flux and velocity ratio has been shown to control whether the flame is stabilized in an attached or detached mode. Increasing the fuel-tooxidizer momentum flux ratio favours the attachment of the stabilized flame. Below a critical momentum flux ratio, the flame becomes detached. The importance of this parameter has also been quoted by other groups for gaseous methane and oxygen injection [8].

Increasing the steady-state chamber pressure is reducing the liftoff distance for detached flames. Previous studies have shown that for higher chamber pressures, methane/oxygen flames stabilize attached to the injector $[4,7]$. For lower pressures, the anchoring of the methane flame seems to be much more dependent on injection parameters $[3,5,8]$.

Concerning CFD simulations, this experimental investigation can provide data with good spatial and temporal resolution. The propellant mass flow rates injected through calibrated sonic nozzles are fixed during the entire duration of the test thus providing reliable data concerning the boundary conditions. The delay between valve opening and ignition time was decreased as much as possible in order to reduce the computational effort. A very small methane annular slit used in test case $\mathrm{C}(0.3 \mathrm{~mm})$ prevents it to be modeled with reliability; however, 
ignition simulation of a stabilized anchored flame (with high reproducibility) is suggested through the tests of series D.

\section{ACKNOWLEDGMENTS}

The work was partly performed within the 'Long-Term Advanced Propulsion Concepts and Technologies' project investigating high-speed air-breathing propulsion. LAPCAT, coordinated by ESA-ESTEC, is supported by the E.U. within the 6th Framework Programme Priority 1.4, Aeronautic and Space, Contract No. AST4-CT-2005-012282. Further info on LAPCAT can be found on http://www.esa.int/techresources/lapcat. ESA-ESTEC is acknowledged for the internal research fellowship granted enabling the present research work.

\section{REFERENCES}

1. Götz, A., C. Máding, L. Brummer, and D. Haeseler. 2001. Application of non toxic propellants for future Advanced Launcher Vehicles. AIAA Paper No. 2001-3546.

2. Baudart, P. A., V. Duthoit, and J. C. Harlay. 1991. Numerical simulation of cryotechnic rocket engine ignition. AIAA Paper No. 91-2290.

3. Cuoco, F., B. Yang, and M. Oschwald. 2004. Experimental investigation of $\mathrm{LOx} / \mathrm{H}_{2}$ and $\mathrm{LOx} / \mathrm{CH}_{4}$ sprays and flames. 24th International Symposium on Space Technology and Science. Japan. Paper No. ISTS 2004-a-04.

4. Candel, S., M. Juniper, G. Singla, P. Scouflaire, and C. Rolon. 2006. Structure and dynamics of cryogenic flames at supercritical pressure. Combust. Sci. Technol. 178(1-3):161-92.

5. Yang, B., F. Cuoco, and M. Oschwald. 2007. Atomization and flames in LOX/H $/ \mathrm{H}_{2}$ and $\mathrm{LOX} / \mathrm{CH}_{4}$ spray combustion. J. Propul. Power 23(4):763-71.

6. Smith, J. J., G. Schneider, D. Suslov, M. Oschwald, and O. Haidn. 2007. Steadystate high pressure $\mathrm{LO}_{x} / \mathrm{H}_{2}$ rocket engine combustion. Aerospace Sci. Technol. 11(1):39-47.

7. Singla, G., P. Scouflaire, C. Rolon, and S. Candel. 2005. Transcritical oxygen/transcritical or supercritical methane combustion. Proc. Combust. Inst. 30(2):2921-28.

8. Moore, J. D., G. A. Risha, K. K. Kuo, B. Zhang, and R. Wehrman. 2003. Stability of methane/oxygen coaxial diffusion flame. 39th AIAA/ASME/SAE/ASEE Conference.

9. Fiock, E. F. 1953. High speed aerodynamics and jet propulsion. Vol. 9: Physical measurements in gas dynamics and combustion. Sec. K: Measurement of Burning Velocity. Princeton, NJ: Princeton Univ. Press. 409-38. 
10. Schmidt, V., D. Klimenko, O. J. Haidn, and M. Oschwald. 2003. Experimental investigation and modelling of ignition transient of a coaxial $\mathrm{H}_{2} / \mathrm{O}_{2}$ injector. 5th Symposium (International) on Liquid Space Propulsion. 28-30.

11. Schmidt, V., U. Wepler, O. J. Haidn, and M. Oschwald. 2004. Characterization of the primary ignition process of a coaxial $\mathrm{GH}_{2} / \mathrm{LOx}$ spray. AIAA Paper No. 20041167.

12. Lacaze, G., B. Cuenot, and T. Poinsot. 2000. LES of laser ignition in a microcombustor. CERFACS Internal Report.

13. Haidn, O. J., I. Palkina, A. Gernoth, and J. R. Riccius. 2007. CFD analysis of a model combustor ignition and comparison with experimental results. AIAA Paper No. 20075441.

14. Cuoco, F., B. Yang, C. Bruno, O. J. Haidn, and M. Oschwald. 2004. Experimental investigation on $\mathrm{LOx} / \mathrm{CH}_{4}$ ignition. AIAA Paper No. 2004-4005.

15. Beduneau, J.-L., B. Kim, L. Zimmer, and Y. Ikeda. 2003. Measurements of minimum ignition energy in premixed laminar methane/air flow by using laser induced spark. Combust. Flame 132(4):653-65.

16. Preclik, D., and P. Spagna. 1989. Low frequency and high frequency combustion oscillation phenomena inside a combustion chamber fed by liquid or gaseous propellants. In: Combustion instabilities in liquid-fuelled propulsion systems: Conference Proceedings of the Propulsion and Energetics Panel (72nd) B Specialists Meeting. 